\title{
Substituição do fubá de milho por gérmen integral de milho na dieta de ovinos
}

\author{
Emmanuelle Cordeiro da Silva(1), Marcelo de Andrade Ferreira ${ }^{(1)}$, Antonia Sherlânea Chaves Véras(1), \\ Safira Valença Bispo(2), Maria Gabriela da Conceição( ${ }^{(1)}$, Michelle Christina Bernardo de Siqueira(1),

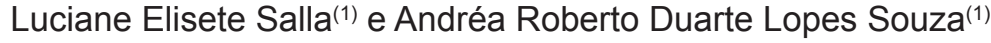

\begin{abstract}
(1)Universidade Federal Rural de Pernambuco, Departamento de Zootecnia, Rua Dom Manoel de Medeiros, s/no, Bairro Dois Irmãos, CEP 52171-900 Recife, PE. E-mail: manuca_cordeiro@hotmail.com, ferreira@dz.ufrpe.br, sherlanea@pq.cnpq.br, gabi2283@hotmail.com, michele.siqueira@gmail.com, lusalla@yahoo.com.br, andreardl_dagher@yahoo.com.br (2)Universidade Federal da Paraíba, Centro de Ciências Agrárias, Campus II, CEP 58397-000 Areia, PB. E-mail: savabi@bol.com.br
\end{abstract}

Resumo - O objetivo deste trabalho foi avaliar o efeito da substituição do fubá de milho pelo gérmen integral de milho, sobre a digestibilidade dos nutrientes na dieta e sobre o desempenho e características de carcaça de ovinos Santa Inês. Quarenta animais, com peso inicial de 17,0 $2,5 \mathrm{~kg}$, foram confinados em baias individuais, em delineamento de blocos ao acaso, com cinco tratamentos e oito repetições. As taxas de substituição foram: $0,25,50,75$ e $100 \%$. Ao abate, foram obtidos os pesos de carcaça quente e de trato digestivo cheio e vazio, a área de olho de lombo, a espessura de gordura subcutânea e o rendimento de cortes comerciais. A substituição do fubá de milho pelo gérmen integral reduziu linearmente o consumo de matéria seca e os coeficientes de digestibilidade de: matéria seca, matéria orgânica, proteína bruta, fibra em detergente neutro e extrato etéreo. A conversão alimentar não foi afetada pelos tratamentos. O ganho médio diário, o peso vivo final, a área de olho de lombo, a espessura de gordura e os rendimentos de carcaça quente e de cortes comerciais diminuíram linearmente com o aumento nos níveis de substituição. A substituição do fubá de milho pelo gérmen integral de milho, nas dietas de ovinos, prejudica o desempenho e as características de carcaça dos animais.

Termos para indexação: aproveitamento de subprodutos, características de carcaça, confinamento, desempenho produtivo, Santa Inês, suplementação alimentar.

\section{Replacement of corn meal by corn germ meal in lamb diets}

\begin{abstract}
The objective of this work was to evaluate the effect of replacing corn meal by corn germ meal on nutrient digestibility in the diet, and on the performance and carcass characteristics of Santa Inês lambs. Forty animals, with $17,0 \pm 2.5 \mathrm{~kg}$ average initial live weight, were housed in individual pens in a randomized block design with five treatments and eight replicates. The replacing rates were $0,25,50,75$, and $100 \%$. Hot carcass weight, full and empty digestive tract weight, ribeye area, fat thickness, and yield of commercial cuts were obtained at slaughter. Corn meal replacement by corn germ meal linearly reduced the dry matter intake and the coefficients of apparent digestibility of: dry matter, organic matter, crude protein, neutral detergent fiber, and ether extract. Feed conversion was not affected by the treatments. Average daily gain, final live weight, loin eye area, fat thickness, and yields of hot carcass and retail cuts decreased linearly with the increasing replacement levels. Replacing corn meal by corn germ meal, in lamb diets, negatively affects the performance and carcass characteristics of the animals.
\end{abstract}

Index terms: utilization of by-products, carcass characteristics, feedlot, productive performance, Santa Inês, feed supplementation.

\section{Introdução}

O milho é produzido em quase todos os continentes. Sua importância econômica advém de suas diversas formas de utilização, que vão da alimentação humana à indústria de alta tecnologia (Froes et al., 2012). A inclusão de subprodutos da industrialização do milho em dietas de ruminantes em confinamento tem sido feita na suplementação alimentar, particularmente com o gérmen integral de milho (GIM), subproduto da trituração do gérmen, do tegumento e das partículas amiláceas, obtidos por extração mecânica (Brito et al., 2005).

O gérmen compõe cerca de $13 \%$ da massa total do grão de milho e pode ser utilizado como concentrado energético, já que armazena a maior parte dos nutrientes do grão. Além de níveis adequados de minerais, fibra e proteína, o GIM possui alto teor de lipídeo (15\%), que o caracteriza como uma importante fonte de energia (Miotto et al., 2009). Assim, a utilização 
deste subproduto na formulação de dietas para ovinos confinados pode ser interessante para os sistemas de produção, por possibilitar o aumento da densidade energética da dieta.

O conhecimento sobre a utilização do GIM nas dietas de ruminantes é escasso na literatura, especialmente para ovinos. Portanto, estudos sobre a substituição de ingredientes convencionais por este subproduto nas rações são pertinentes. A inclusão de GIM nas dietas de ovinos deve ser feita com cautela para evitar efeitos negativos das gorduras sobre a digestão dos alimentos e o comprometimento do consumo de matéria seca e ganho de peso (Jenkins et al., 2008). O limite de extrato etéreo na matéria seca não deve ultrapassar $6 \%$, na dieta de ruminantes, embora alguns resultados de pesquisa apontem que o nível de inclusão pode ser maior, sem que haja prejuízo ao desempenho dos animais (Jordan et al., 2006; Jenkins et al., 2008).

O objetivo deste trabalho foi avaliar o efeito da substituição do fubá de milho pelo gérmen integral de milho, sobre a digestibilidade dos nutrientes na dieta e sobre o desempenho e características de carcaça de ovinos Santa Inês confinados.

\section{Material e Métodos}

O experimento foi realizado no Departamento de Zootecnia da Universidade Federal Rural de Pernambuco (UFRPE), em Recife, PE. Foram confinados, em baias individuais providas de comedouros e bebedouros, por 70 dias, 40 ovinos Santa Inês de cinco meses, com $17,0 \pm 2,5 \mathrm{~kg}$ de peso vivo inicial. Os animais foram distribuídos em cinco tratamentos referentes aos níveis de substituição do fubá de milho pelo gérmem integral de milho, GIM (Tabelas 1 e 2). Os níveis de substituição avaliados foram os seguintes: $0,25,50,75$ e $100 \%$. A dieta sem o GIM foi formulada para atender às exigências de mantença e ganho médio diário de $200 \mathrm{~g}$ por dia, de um ovino macho com peso vivo médio de $25 \mathrm{~kg}$ (National Research Council, 2007).

Os animais foram adaptados às dietas por 30 dias. Na primeira semana, foi fornecido somente o volumoso e, nas semanas seguintes, aumentou-se gradativamente a quantidade do concentrado na dieta, até a proporção das rações experimentais (50:50). Ao fim do período de adaptação, os ovinos foram pesados em jejum, tendo-se obtido o peso vivo inicial para a formação dos blocos.

A dieta foi fornecida duas vezes ao dia e a oferta foi ajustada a cada três dias, de acordo com o consumo médio dos três dias anteriores. As dietas, o volumoso e o concentrado ofertados a cada animal, assim como as sobras, foram amostrados semanalmente, no total de dez amostras por animal, em 70 dias de experimento. As amostras foram armazenadas em freezer à $-10^{\circ} \mathrm{C}$ e, posteriormente, foram descongeladas, pré-secadas em estufa de ventilação forçada a $65^{\circ} \mathrm{C}$, por 72 horas, e trituradas em moinho do tipo Willey (de facas), com peneira de $1 \mathrm{~mm}$. Após a secagem e o processamento, todas as amostras foram homogeneizadas para a retirada de uma amostra representativa, com cerca de $10 \%$ do peso total das amostras homogeneizadas, para posteriores análises bromatológicas.

Após 40 dias de experimento, a digestibilidade dos nutrientes foi avaliada em um ensaio de sete dias. Para obtenção da estimativa de nutrientes digestíveis totais (NDT), foi utilizada lignina purificada de eucalipto enriquecida LIPE, (P2S2, Florestal, MG) como marcador externo, oferecida aos animais diariamente, às $8 \mathrm{~h}$ da manhã, por meio de uma cápsula de $250 \mathrm{mg}$, tendo-se utilizado dois dias para adaptação dos animais, e cinco dias para coleta das fezes. As amostras de fezes foram colhidas diretamente do reto, em diferentes

Tabela 1. Composição bromatológica dos ingredientes utilizados nas dietas.

\begin{tabular}{|c|c|c|c|c|c|c|c|c|c|c|}
\hline Ingrediente & $\begin{array}{c}\text { Matéria seca } \\
(\%)\end{array}$ & Matéria mineral & Extrato etéreo & Proteína bruta & $\begin{aligned} & \text { FDN } \\
&-(\% \mathrm{da}\end{aligned}$ & FDA & CHOT & $\mathrm{CNF}$ & PIDN & Lignina \\
\hline Feno de capim Tifton & 86,8 & 74,4 & 19,3 & 8,6 & 70,5 & 32,3 & 82,0 & 11,6 & 33,7 & 44,9 \\
\hline Gérmen de milho & 90,7 & 13,1 & 42,5 & 10,7 & 44,1 & 14,2 & 45,4 & 13,1 & 48,9 & 22,4 \\
\hline Farelo de soja & 87,1 & 70,2 & 33,5 & 44,2 & 16,7 & 6,3 & 45,5 & 28,8 & 75,9 & 2,3 \\
\hline Fubá de milho & 87,2 & 18,7 & 56,5 & 8,24 & 10,9 & 30,1 & 84,3 & 73,4 & 13,5 & 5,8 \\
\hline Farelo de trigo & 88,0 & 51,9 & 36,2 & 16,4 & 38,2 & 11,5 & 74,8 & 36,6 & 21,9 & 28,3 \\
\hline Cloreto de sódio & 99,0 & 99,9 & - & - & - & - & - & - & - & - \\
\hline Mistura mineral & 99,0 & 99,9 & - & - & - & - & - & - & - & - \\
\hline
\end{tabular}

FDN, fibra em detergente neutro; FDA, fibra em detergente ácido; CHOT, carboidratos totais; CNF, carboidratos não fibrosos; PIDN, proteína indigestível em detergente neutro. 
horários (Ferreira et al., 2009): $1^{\circ}$ dia, às $7 \mathrm{~h} ; 2^{\circ}$ dia, às $9 \mathrm{~h} ; 3^{\circ}$ dia, às $11 \mathrm{~h} ; 4^{\circ}$ dia, às $13 \mathrm{~h}$; e $5^{\circ}$ dia, às $15 \mathrm{~h}$.

As amostras de fezes (total de cinco amostras por animal) foram congeladas em freezer a $-10^{\circ} \mathrm{C}$. No final do período de coleta (após os sete dias), as amostras de fezes de cada animal foram descongeladas, pré-secadas em estufa de ventilação forçada a $65^{\circ} \mathrm{C}$, por 72 horas, homogeneizadas e pesadas. Do peso total das amostras obtido, 10\% foram retirados para formação da amostra composta de fezes de cada animal que, depois, foram trituradas em moinho do tipo Willey, com peneira de $1 \mathrm{~mm}$, para análises posteriores, conforme Saliba et al. (2003).

As análises bromatológicas foram realizadas no Laboratório de Nutrição Animal do Departamento de Zootecnia da UFRPE. Foram determinados os teores de matéria seca (MS), matéria mineral (MM), matéria orgânica (MO), proteína bruta (PB) e fibra em detergente ácido (FDA) dos alimentos ofertados, das sobras e das fezes, segundo a metodologia descrita por Silva \& Queiroz (2002). A fibra em detergente neutro (FDN) foi obtida conforme Licitra et al. (1996). Utilizou-se autoclave para a determinação de FDN e FDA, e sacos de TNT (tecido não tecido) para determinação da fibra.

Os teores de proteína insolúvel em detergente neutro (PIDN) dos alimentos foram estimados nos resíduos, após as amostras compostas de volumoso e concentrado terem sido submetidas à lavagem com

Tabela 2. Composição centesimal e bromatológica das dietas, com base na matéria seca (\%).

\begin{tabular}{lccccc}
\hline Ingrediente & \multicolumn{5}{c}{ Níveis de substituição (\%) } \\
\cline { 2 - 6 } & 0 & 25 & 50 & 75 & 100 \\
\hline Feno de capim Tifton & 50,0 & 50,0 & 50,0 & 50,0 & 50,0 \\
Gérmen integral de milho & - & 6,0 & 12,0 & 18,0 & 24,0 \\
Milho moído & 24,0 & 18,0 & 12,0 & 6,0 & - \\
Farelo de soja & 14,5 & 14,0 & 13,5 & 13,0 & 12,5 \\
Farelo de trigo & 10,0 & 10,5 & 11,0 & 11,5 & 12,0 \\
Cloreto de sódio & 0,5 & 0,5 & 0,5 & 0,5 & 0,5 \\
Mistura mineral & 1,0 & 1,0 & 1,0 & 1,0 & 1,0 \\
\hline Composição bromatológica (\%) & & & & & \\
Matéria seca & 87,20 & 87,41 & 87,62 & 87,83 & 88,04 \\
Proteína bruta & 14,33 & 14,34 & 14,35 & 14,36 & 14,37 \\
Extrato etéreo & 3,17 & 5,38 & 7,60 & 9,81 & 12,03 \\
Matéria mineral & 5,71 & 5,66 & 5,62 & 5,58 & 5,53 \\
Fibra em detergente neutro & 44,09 & 46,37 & 48,66 & 50,94 & 53,22 \\
Fibra em detergente ácido & 18,92 & 19,62 & 20,31 & 21,01 & 21,71 \\
Lignina & 2,70 & 2,82 & 2,93 & 3,04 & 3,15 \\
PIDN ${ }^{(1)}$ & 3,33 & 3,51 & 3,70 & 3,89 & 4,07 \\
\hline
\end{tabular}

(1)Proteína insolúvel em detergente neutro. detergente neutro (Licitra et al., 1996). A lignina foi medida por meio de solubilização da celulose em ácido sulfúrico $\left(\mathrm{H}_{2} \mathrm{SO}_{4}\right)$ a $72 \%$ (Detmann et al., 2012).

Os carboidratos totais (CHOT) e os carboidratos não fibrosos (CNF) da dieta foram estimados conforme Sniffen et al. (1992), pelas seguintes equações: $\mathrm{CHOT}=100-\% \mathrm{~PB}-\% \mathrm{EE}-\%$ cinzas e $\mathrm{CNF}=\mathrm{CHOT}-\% \mathrm{FDN}$, em que PB é a percentagem de proteína bruta, EE é a percentagem de extrato etéreo e FDN é a percentagem de fibra em detergente neutro.

O consumo de nutrientes digestíveis totais (CNDT) foi estimado pela equação descrita por Weiss (1999): $\mathrm{CNDT}=\mathrm{PBD}+2,25 \times \mathrm{EED}+\mathrm{CNFD}+\mathrm{FDND}$, em que a proteína bruta digestível foi obtida pela fórmula $\mathrm{PBD}=\mathrm{PB}$ ingerida - $\mathrm{PB}$ fezes; o extrato etéreo digestível, por EED = EE ingerido - EE fezes; os carboidratos não fibrosos digestíveis, por $\mathrm{CNFD}=\mathrm{CNF}$ ingeridos $-\mathrm{CNF}$ fezes; a fibra em detergente neutro digestível, por FDND $=$ FDN ingerido - FDN fezes; os teores de nutrientes digestíveis totais NDT na MS $\left(\mathrm{g} \mathrm{kg}^{-1}\right)$.

Após 70 dias, os animais foram submetidos a jejum de sólidos por 12 horas e, imediatamente antes do abate, foram pesados para obtenção do peso corporal ao abate (PCA) e ganho médio diário. Ao abate, os animais foram insensibilizados por concussão cerebral, por meio de percussão não penetrante, seguido de sangria por 4 min, por meio da secção da carótida e jugular (Cezar \& Sousa, 2007). O sangue foi recolhido e pesado imediatamente.

Após a esfola e evisceração, foram retiradas a cabeça, por secção na articulação atlanto-occipital, e as patas, por secção nas articulações carpo e metatarsianas; em seguida, registrou-se o peso da carcaça quente (PCQ), incluídos os rins e a gordura pélvico-renal. $\mathrm{O}$ trato gastrintestinal (TGI), cheio e vazio, foi pesado para determinação do peso do corpo vazio (PCV) e do rendimento biológico ou verdadeiro, conforme Silva Sobrinho \& Silva (2000), como: $\mathrm{RV}(\%)=100 \times \mathrm{PCQ} / \mathrm{PCV}$.

As carcaças foram resfriadas em câmara frigorífica, por 24 horas, $\mathrm{a} \pm 4^{\circ} \mathrm{C}$, penduradas pelo tendão calcâneo comum, com as articulações metatarsianas distanciadas em $17 \mathrm{~cm}$. Decorridas 24 horas, as carcaças foram pesadas, tendo-se descontado os pesos dos rins e da gordura perirrenal, para obtenção do peso da carcaça fria (PCF) e do cálculo da perda por resfriamento: $\mathrm{PR}(\%)=100 \times(\mathrm{PCQ}-\mathrm{PCF}) / \mathrm{PCQ} . \mathrm{O}$ rendimento 
de carcaça quente foi calculado pela seguinte equação: RCQ $(\%)=100 \times \mathrm{PCQ} / \mathrm{PCA}$, e o rendimento comercial como RC $(\%)=100 \times \mathrm{PCF} / \mathrm{PCA}$ (Silva Sobrinho \& Silva, 2000).

Após a pesagem, as carcaças frias foram seccionadas ao meio, e as meias-carcaças foram pesadas. As carcaças esquerdas foram seccionadas em seis regiões anatômicas: pescoço, entre a $1^{\mathrm{a}}$ e a $7^{\text {a }}$ vértebras cervicais; as costelas verdadeiras, entre a $1^{\mathrm{a}}$ e a $5^{\mathrm{a}}$ vértebras torácicas; o lombo, entre a $1^{\mathrm{a}} \mathrm{e}$ $6^{\text {a }}$ vértebras lombares; a perna, a última vértebra lombar e a primeira sacra, sendo considerada a base óssea do tarso, tíbia, fêmur, ísquio, ílio, púbis, vértebras sacras e as duas primeiras vértebras coccídeas; a paleta, região obtida pela desarticulação da escápula, úmero, rádio, ulna e carpo; e o serrote, obtido pelo corte em linha reta, do flanco até a extremidade cranial do manúbrio do esterno, segundo metodologia adaptada de Cezar \& Sousa (2007). Foram registrados os pesos individuais de cada corte e, posteriormente, foi calculada a proporção de cada corte oriundo da meia-carcaça esquerda, em relação ao peso reconstituído da mesma carcaça, para obtenção do rendimento dos cortes comerciais.

Foi feito um corte transversal entre a $12^{\mathrm{a}}$ e a $13^{\mathrm{a}}$ costelas, para mensuração da área de olho de lombo (AOL) do músculo longissimus dorsi, pelo traçado do contorno do músculo em folha plástica de transparência, para posterior determinação da área em planímetro digital Digiplan, (HAFF, Pfronten, Alemanha), tendose utilizado a média de três leituras (Cezar \& Sousa, 2007). Também no longissimus dorsi, por meio de um paquímetro digital, foi medida a espessura de gordura subcutânea (EGS) sobre a secção do músculo (entre a última vértebra torácica e a primeira lombar), a dois terços do comprimento total da área de olho de lombo.

Utilizou-se o delineamento de blocos ao acaso com cinco tratamentos e oito repetições. Os blocos foram formados de acordo com o peso inicial dos animais. Os dados foram submetidos a análises de variância e regressão, e os modelos foram escolhidos com base na significância dos coeficientes de regressão, avaliada pelo teste t. As análises estatísticas foram realizadas por meio do Saeg (2007).

\section{Resultados e Discussão}

O consumo de matéria seca dos ovinos confinados diminuiu linearmente com o aumento dos níveis de substituição do fubá de milho pelo GIM nas dietas (Tabela 3). Constatou-se a redução de $0,004 \mathrm{~kg}$ por dia no consumo de matéria seca, para cada $1 \%$ de substituição. Consequentemente, houve redução linear também no consumo de proteína bruta, fibra em detergente neutro e de nutrientes digestíveis totais.

Estes resultados estão de acordo com os obtidos por Montgomery et al. (2005), que avaliaram o desempenho de bovinos de corte em terminação sob diferentes níveis de suplementação com GIM. Luginbuhl et al. (2000) avaliaram cabritos confinados, alimentados com dietas a $0,8,16$ e $24 \%$ de caroço de algodão, e observaram redução do consumo em consequência do aumento no teor de gordura. Urano et al. (2006) também observaram redução do consumo de alimentos, quando elevaram o teor de gordura na dieta de ovinos confinados.

Os coeficientes de digestibilidade dos nutrientes diminuíram linearmente com o aumento dos níveis de substituição, especialmente o da fibra em detergente neutro (Tabela 3). Houve redução de $0,301 \mathrm{~kg}$ por dia no coeficiente de digestibilidade da MS, para cada $1 \%$ de substituição do fubá pelo GIM. Rogério et al. (2004), apesar de não terem constatado efeito significativo da inclusão de caroço de algodão na dieta sobre o consumo de matéria seca, relataram redução linear dos coeficientes de digestibilidade da fração fibrosa, o que também foi observado por Palmiquist \& Mattos (2006).

Os mecanismos fisiológicos envolvidos na redução do consumo de matéria seca pela inclusão de fontes de gordura na dieta de ruminantes ainda não estão bem elucidados na literatura. Já a redução da digestibilidade dos nutrientes pode estar associada aos efeitos químicos do maior aporte de ácidos graxos insaturados no rúmen e intestinos, em dietas ricas em gorduras. Segundo Jenkins \& McGuire (2006), efeitos tóxicos dos ácidos graxos aos microrganismos podem ocorrer. Além desse possível efeito citotóxico, a redução da digestibilidade dos nutrientes pode resultar de um efeito físico das gorduras no ambiente ruminal, que dificultaria a aderência dos microrganismos à superfície da fibra e impediria a ação das celulases necessárias para iniciar a degradação (Sullivan et al., 2004). A redução na digestibilidade dos nutrientes leva ao aumento do conteúdo ruminal acumulado e limita a ingestão. $\mathrm{O}$ aumento linear do peso do conteúdo 
do trato gastrintestinal cheio, peso do rúmen e peso do trato gastrintestinal cheio, e a diminuição do peso do rúmen e trato gastrintestinal vazio, observados no presente trabalho em consequência do aumento da proporção de GIM na dieta (Tabela 4), reforçam esta hipótese.

O peso vivo final e ganho de peso médio diário diminuíram linearmente, em razão dos níveis de substituição (Tabela 5). A cada $1 \%$ de substituição, houve redução de $0,0471 \mathrm{~g}$ e $0,0006 \mathrm{~g}$, por dia no ganho de peso total e ganho médio diário, respectivamente.

Os tratamentos não afetaram a conversão alimentar, o que está de acordo com os resultados obtidos por Luginbuhl et al. (2000). Os autores observaram que a redução do consumo causada pela maior inclusão de EE na dieta, resultou em menor aporte de energia disponível para atendimento das exigências de mantença e produção dos animais, e comprometeu o ganho de peso.
O aumento dos níveis de substituição, especialmente a 75 e 100\%, resultaram em dietas com teores de gordura bem acima do recomendado: 9,8 e $12 \%$ de EE, respectivamente. A redução linear do ganho de peso e do peso corporal dos animais resultou na produção de animais mais leves ao abate e, consequentemente, com carcaças menores. O peso de carcaça (quente e fria), o rendimento de carcaça (quente e fria), e a área de olho de lombo diminuíram com o aumento dos níveis de substituição (Tabela 5).

Os principais responsáveis pelo valor comercial da carcaça são o peso vivo final e o rendimento, características fortemente associadas ao peso do conteúdo do trato gastrintestinal e dos órgãos internos (Kadim et al., 2003). O aumento linear no peso do trato gastrintestinal cheio e no conteúdo do trato gastrintestinal, observado no presente trabalho com os maiores níveis de substituição (Tabela 4), determinaram a diminuição linear do rendimento de carcaça.

Tabela 3. Consumo e coeficientes de digestibilidade de ovinos em confinamento, alimentados com gérmen integral do milho (GIM), em níveis crescentes de substituição ao fubá de milho.

\begin{tabular}{|c|c|c|c|c|c|c|c|c|}
\hline \multirow[t]{2}{*}{ Variável } & \multicolumn{5}{|c|}{ Níveis de substituição (\%) } & \multirow[t]{2}{*}{ Equação de regressão } & \multirow[t]{2}{*}{$\mathrm{R}^{2}$} & \multirow{2}{*}{$\begin{array}{l}\text { CV } \\
(\%)\end{array}$} \\
\hline & 0 & 25 & 50 & 75 & 100 & & & \\
\hline & \multicolumn{8}{|c|}{ Consumo de nutrientes (kg por dia) } \\
\hline Matéria seca & 1,002 & 0,939 & 0,753 & 0,650 & 0,639 & $\hat{\mathrm{Y}}=1,0248-0,004 \mathrm{GIM}^{* * *}$ & 0,93 & 11,18 \\
\hline Matéria orgânica & 0,945 & 0,887 & 0,711 & 0,614 & 0,605 & $\hat{\mathrm{Y}}=0,9663-0,0038 \mathrm{GIM}^{* * *}$ & 0,93 & 11,13 \\
\hline Proteína bruta & 0,152 & 0,145 & 0,118 & 0,103 & 0,099 & $\hat{\mathrm{Y}}=0,1566-0,0006 \mathrm{GIM} * * *$ & 0,94 & 11,04 \\
\hline FDN & 0,425 & 0,421 & 0,351 & 0,319 & 0,329 & $\hat{\mathrm{Y}}=0,4395-0,0012 \mathrm{GIM} * * *$ & 0,84 & 11,91 \\
\hline Extrato etéreo & 0,032 & 0,052 & 0,061 & 0,069 & 0,085 & $\hat{\mathrm{Y}}=0,0370+0,0005 \mathrm{GIM}^{* * *}$ & 0,97 & 12,93 \\
\hline \multirow[t]{2}{*}{ NDT } & 0,830 & 0,766 & 0,474 & 0,337 & 0,312 & $\hat{\mathrm{Y}}=0,8585-0,0058 \mathrm{GIM}^{* * *}$ & 0,93 & 19,82 \\
\hline & \multicolumn{8}{|c|}{ Coeficiente de digestibilidade $(\%)$} \\
\hline Matéria seca & 71,7 & 68,2 & 57,5 & 45,8 & 45,1 & $\hat{\mathrm{Y}}=73,97-0,301 \mathrm{GIM}^{* * *}$ & 0,95 & 12,31 \\
\hline Matéria orgânica & 72,5 & 68,5 & 57,9 & 46,6 & 46,0 & $\hat{\mathrm{Y}}=74,45-0,290 \mathrm{GIM}^{* * *}$ & 0,95 & 12,32 \\
\hline Proteína bruta & 83,4 & 81,0 & 74,2 & 63,7 & 56,1 & $\hat{\mathrm{Y}}=86,62-0,288 \mathrm{GIM}^{* * *}$ & 0,96 & 15,78 \\
\hline FDN & 65,0 & 63,3 & 50,8 & 45,5 & 47,7 & $\hat{\mathrm{Y}}=66,09-0,208 \mathrm{GIM}^{* * *}$ & 0,84 & 14,08 \\
\hline Extrato etéreo & 91,4 & 89,5 & 91,2 & 82,8 & 55,8 & $\hat{\mathrm{Y}}=97,86-0,313 \mathrm{GIM}^{* * *}$ & 0,68 & 14,07 \\
\hline NDT & 74,4 & 78,6 & 62,7 & 55,5 & 53,0 & $\hat{\mathrm{Y}}=82,62-0,840 \mathrm{GIM}^{* * *}$ & 0,85 & 11,84 \\
\hline
\end{tabular}

*** Significativo a $0,1 \%$ de probabilidade. FDN, fibra em detergente neutro; NDT, nutrientes digestíveis totais.

Tabela 4. Peso $(\mathrm{kg})$ de rúmen cheio, rúmen vazio, do trato gastrintestinal (TGI) cheio e vazio, e do conteúdo do trato gastrintestinal de ovinos, alimentados com gérmen integral do milho (GIM), em níveis crescentes de substituição ao fubá de milho.

\begin{tabular}{|c|c|c|c|c|c|c|c|c|}
\hline \multirow[t]{2}{*}{ Variável } & \multicolumn{5}{|c|}{ Níveis de substituição (\%) } & \multirow[t]{2}{*}{ Equação de regressão } & \multirow[t]{2}{*}{$\mathrm{R}^{2}$} & \multirow{2}{*}{$\begin{array}{l}\mathrm{CV} \\
(\%)\end{array}$} \\
\hline & 0 & 25 & 50 & 75 & 100 & & & \\
\hline Rúmen cheio & 3,88 & 4,58 & 5,70 & 6,06 & 5,80 & $\hat{\mathrm{Y}}=4,2507+0,0211 \mathrm{GIM}^{* *}$ & 0,82 & 19,7 \\
\hline Rúmen vazio & 0,59 & 0,56 & 0,53 & 0,50 & 0,46 & $\hat{\mathrm{Y}}=0,6052-0,0013 \mathrm{GIM} * *$ & 0,99 & 13,7 \\
\hline TGI cheio & 7,19 & 8,08 & 8,74 & 9,03 & 8,70 & $\hat{\mathrm{Y}}=7,7729+0,0157 \mathrm{GIM}^{*} *$ & 0,74 & 14,4 \\
\hline TGI vazio & 1,92 & 2,07 & 1,77 & 1,67 & 1,56 & $\hat{\mathrm{Y}}=2,0703-0,0044 \mathrm{GIM} * *$ & 0,76 & 9,88 \\
\hline Conteúdo do TGI & 5,27 & 6,01 & 6,97 & 7,36 & 7,15 & $\hat{\mathrm{Y}}=5,7025+0,0202 \mathrm{GIM}^{* *}$ & 0,84 & 17,2 \\
\hline
\end{tabular}

**Significativo a $1 \%$ de probabilidade. 
A perda por resfriamento e a espessura de gordura de cobertura (EGC) não foram afetadas pela substituição. A perda por resfriamento está associada à EGC e à perda de umidade (Osório et al., 2003). Como não houve efeito dos níveis de substituição sobre a EGC, e como esta tem a função de proteger as carcaças contra o ressecamento causado pelo resfriamento, a ausência de efeito dos tratamentos sobre a perda por resfriamento é um resultado coerente.

Para área de olho de lombo (AOL), que é uma característica relacionada à musculosidade do animal (Clementino et al., 2007), o tamanho da carcaça é determinante. Assim, a AOL diminuiu linearmente com a inclusão de GIM à dieta, em razão da redução do peso das carcaças com aumento dos níveis de substituição. Os pesos absolutos dos cortes cárneos também apresentaram o mesmo comportamento (Tabela 6).

Já os rendimentos dos cortes cárneos não foram influenciados pelos tratamentos, exceto os de rendimento do pernil, que aumentou linearmente com o aumento dos níveis de substituição. Dos cortes estudados, o pernil desenvolve-se mais precocemente (Osório et al., 2003), o que permite inferir que os

Tabela 5. Desempenho e rendimentos de carcaça de ovinos em confinamento, alimentados com gérmen integral do milho (GIM), em níveis crescentes de substituição ao fubá de milho.

\begin{tabular}{|c|c|c|c|c|c|c|c|c|}
\hline \multirow[t]{2}{*}{ Variável } & \multicolumn{5}{|c|}{ Níveis de substituição (\%) } & \multirow[t]{2}{*}{ Equação de regressão } & \multirow[t]{2}{*}{$\mathrm{R}^{2}$} & \multirow{2}{*}{$\begin{array}{l}\text { CV } \\
(\%)\end{array}$} \\
\hline & 0 & 25 & 50 & 75 & 100 & & & \\
\hline \multicolumn{9}{|c|}{ Desempenho } \\
\hline Peso vivo inicial & 17,65 & 17,78 & 17,43 & 17,63 & 17,63 & - & - & - \\
\hline Peso vivo final & 29,61 & 30,22 & 28,23 & 25,94 & 25,77 & $\hat{\mathrm{Y}}=31,285-0,0479 \mathrm{GIM}^{* * *}$ & 0,85 & 6,91 \\
\hline Ganho médio diário & 0,170 & 0,177 & 0,149 & 0,118 & 0,119 & $\hat{\mathrm{Y}}=0,184-0,0006 \mathrm{GIM}^{* * *}$ & 0,86 & 18,35 \\
\hline Conversão alimentar & 5,97 & 5,47 & 5,07 & 5,85 & 5,61 & ns & - & 17,02 \\
\hline \multicolumn{9}{|c|}{ Características de carcaça } \\
\hline Peso carcaça quente & 13,71 & 13,45 & 11,7 & 10,16 & 10,01 & $\hat{\mathrm{Y}}=14,399-0,0428 \mathrm{GIM} * * *$ & 0,93 & 6,87 \\
\hline Peso carcaça fria & 13,25 & 13,01 & 11,37 & 9,83 & 9,53 & $\hat{\mathrm{Y}}=13,961-0,0425$ GIM $* * *$ & 0,94 & 7,2 \\
\hline Rendimento carcaça quente & 44,38 & 42,58 & 39,36 & 37,93 & 37,13 & $\hat{\mathrm{Y}}=44,341-0,0767$ GIM $* * *$ & 0,96 & 4,44 \\
\hline Rendimento carcaça fria & 42,89 & 41,12 & 38,15 & 36,7 & 35,23 & $\hat{\mathrm{Y}}=42,977-0,0791 \mathrm{GIM} * * *$ & 0,98 & 4,67 \\
\hline Perda por resfriamento & 3,23 & 3,31 & 2,97 & 3,14 & 4,84 & ns & - & 39,07 \\
\hline Espessura capa de gordura & 0,64 & 0,59 & 0,78 & 0,42 & 0,57 & ns & - & 39,78 \\
\hline Área d olho de lombo & 10,04 & 9,78 & 8,43 & 7,29 & 6,72 & $\hat{\mathrm{Y}}=0,6755-0,0011 \mathrm{GIM} * * *$ & 0,97 & 15,3 \\
\hline
\end{tabular}

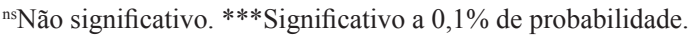

Tabela 6. Pesos absolutos e rendimento dos cortes comerciais de ovinos, alimentados com gérmen integral do milho (GIM), em níveis crescentes de substituição ao fubá de milho.

\begin{tabular}{|c|c|c|c|c|c|c|c|c|}
\hline \multirow[t]{2}{*}{ Variável } & \multicolumn{5}{|c|}{ Níveis de substituição (\%) } & \multirow[t]{2}{*}{ Equação de regressão } & \multirow[t]{2}{*}{$\mathrm{R}^{2}$} & \multirow{2}{*}{$\begin{array}{l}\text { CV } \\
(\%)\end{array}$} \\
\hline & 0 & 25 & 50 & 75 & 100 & & & \\
\hline \multicolumn{9}{|c|}{ Peso absoluto dos cortes (kg) } \\
\hline Pescoço & 0,604 & 0,618 & 0,547 & 0,463 & 0,434 & $\hat{\mathrm{Y}}=0,6532-0,0020 \mathrm{GIM}^{* * *}$ & 0,90 & 12,28 \\
\hline Paleta & 1,282 & 1,240 & 1,034 & 0,949 & 0,892 & $\hat{\mathrm{Y}}=1,3359-0,0043 \mathrm{GIM}^{* * *}$ & 0,95 & 7,42 \\
\hline Costelas & 1,010 & 1,010 & 0,882 & 0,716 & 0,698 & $\hat{\mathrm{Y}}=1,0817-0,0037 \mathrm{GIM}^{* * *}$ & 0,91 & 9,87 \\
\hline Serrote & 0,737 & 0,674 & 0,591 & 0,511 & 0,507 & $\hat{\mathrm{Y}}=0,7516-0,0025 \mathrm{GIM}^{* * *}$ & 0,95 & 11,45 \\
\hline Lombo & 0,526 & 0,490 & 0,464 & 0,379 & 0,353 & $\hat{\mathrm{Y}}=0,5501-0,0018 \mathrm{GIM}^{* * *}$ & 0,97 & 9,08 \\
\hline$\underline{\text { Pernil }}$ & 2,16 & 2,18 & 1,88 & 1,71 & 1,64 & $\hat{\mathrm{Y}}=2,2904-0,0060 \mathrm{GIM} * * *$ & 0,91 & 6,85 \\
\hline \multicolumn{9}{|c|}{ Rendimento dos cortes $(\%)$} \\
\hline Pescoço & 9,48 & 9,89 & 10,04 & 9,79 & 9,56 & ns & - & 9,19 \\
\hline Paleta & 20,31 & 20,03 & 19,18 & 20,06 & 19,72 & ns & - & 3,51 \\
\hline Costelas & 15,87 & 16,12 & 16,36 & 15,25 & 15,41 & ns & - & 6,76 \\
\hline Serrote & 11,71 & 10,90 & 11,05 & 10,82 & 11,21 & $\mathrm{~ns}$ & - & 7,47 \\
\hline Lombo & 8,34 & 7,91 & 8,49 & 8,01 & 7,77 & ns & - & 8,02 \\
\hline Pernil & 34,28 & 35,14 & 34,88 & 36,06 & 36,33 & $\hat{\mathrm{Y}}=34,38+0,0197 \mathrm{GIM} * * *$ & 0,89 & 2,76 \\
\hline
\end{tabular}

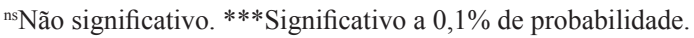


menores ganho de peso e peso de carcaça causaram menor prejuízo a seu desenvolvimento completo, o que tornou esse corte proporcionalmente maior na carcaça, em comparação aos os demais cortes.

\section{Conclusão}

A substituição do fubá de milho pelo gérmen integral de milho, em dietas de ovinos confinados Santa Inês, prejudica o desempenho e as características de carcaça dos animais.

\section{Referências}

BRITO, A.B.; STRINGHINI, J.H.; CRUZ, C.P.; XAVIER, S.A.G.; LEANDRO, N.S.M.; CAFÉ, M.B. Efeito do gérmen integral de milho sobre o desempenho e rendimento de carcaça de frangos de corte. Arquivos Brasileiro de Medicina Veterinária e Zootecnia, v.57, p.241-249, 2005. DOI: 10.1590/ S0102-09352005000200017.

CEZAR, M.F.; SOUSA, W.H. de. Carcaças ovinas e caprinas: obtenção, avaliação e tipificação. Campina Grande: Agropecuária Tropical, 2007. 120p.

CLEMENTINO, R.H.; SOUSA, W.H. de; MEDEIROS, A.N. de; CUNHA, M. das G.G.; GONZAGA NETO, S.; CARVALHO, F.F.R. de; CAVALCANTE, M.A. Influência dos níveis de concentrado sobre os cortes comerciais, os constituintes não carcaça e os componentes da perna de cordeiro confinados. Revista Brasileira de Zootecnia, v.36, p.681-688, 2007. DOI: 10.1590/ S1516-35982007000300023.

DETMANN, E.; SOUZA, M.A. de; VALADARES FILHO, S. de C.; QUEIROZ, A.C. de; BERCHIELLI, T.T.; SALIBA, E. de O.S.; CABRAL, L. da S.; PINA, D. dos S.; LADEIRA, M.M.; AZEVEDO, J.A.G. (Ed.). Métodos para análise de alimentos. Visconde do Rio Branco: Suprema, 2012. 214p.

FERREIRA, M. de A.; VALADARES FILHO, S. de C.; MARCONDES, M.I.; PAIXÃO, M.L.; PAULINO, M.F.; VALADARES, R.F.D. Avaliação de indicadores em estudos com ruminantes: digestibilidade. Revista Brasileira de Zootecnia, v.38, p.1568-1573, 2009. DOI: 10.1590/ S1516-35982009000800022.

FROES, L. de O.; FALQUETO, M.A.O.; CASTRO, M.V.L. de; NAVES, M.M.V. Gérmen com pericarpo de milho desengordurado na formulação de biscoitos tipo cookie. Ciência Rural, v.42, p.744-750, 2012. DOI: 10.1590/S0103-84782012000400028.

JENKINS, T.C.; MCGUIRE, M.A. Major advances in nutrition: impact on milk composition. Journal of Dairy Science, v.89, p.1302-1310, 2006. DOI: 10.3168/jds.S0022-0302(06)72198-1.

JENKINS, T.C.; WALLACE, R.J.; MOATE, P.J.; MOSLEY, E.E. Recent advances in biohydrogenation of unsaturated fatty acids within the rumen microbial ecosystem. Journal of Animal Science, v.86, p.397-412, 2008. DOI: 10.2527/jas.2007-0588.

KADIM, I.T.; MAHGOUB, O.; AL-AJMI, D.S.; AL-MAQBALY, R.S.; SAGRI, N.M.; RITCHIE, A. An evaluation of the growth, carcass and meat quality characteristics of Omani goat breeds. Meat Science, v.66, p.203-210, 2003. DOI: 10.1016/ S0309-1740(03)00092-5.

LICITRA, G.; HERNANDES, T.M.; VAN SOEST, P.J. Standardization of procedures for nitrogen fractionation of ruminant feeds. Animal Feed Science and Technology, v.57, p.347-358, 1996. DOI: 10.1016/0377-8401(95)00837-3.

LUGINBUHL, J.M.; POORE, M.H.; CONRAD, A.P. Effect of level of whole cottonseed on intake, digestibility, and performance of growing male goats fed hay-based diets. Journal of Animal Science, v.78, p.1677-1683, 2000.

MIOTTO, F.R.C.; NEIVA, J.N.M.; VOLTOLINI, T.V.; ROGÉRIO, M.C.P.; CASTRO, K.J. de. Desempenho produtivo de tourinhos Nelore x Limousin alimentados com dietas contendo gérmen de milho integral. Revista Ciência Agronômica, v.40, p.624-632, 2009.

MONTGOMERY, S.P.; DROVILLARD, J.S.; SINDT, J.J.; GREENQUIST, M.A.; DEPENBUSCH, B.E.; GOOD, E.J.; LOE, E.R.; SULPIZIO, M.J.; KESSEN, T.J.; ETHINGTON, R.T. Effects of dried full-fat corn germ and vitamin $\mathrm{E}$ on growth performance and carcass characteristics of finishing cattle. Journal of Animal Science, v.83, p.2440-2447, 2005.

NATIONAL RESEARCH COUNCIL. Nutrient requirements of small ruminants: sheep, goats, cervids, and new world camelids. Washington: NRC, 2007. 384p.

OSÓRIO, J.C. da S.; OSÓRIO, M.T.M. Produção de carne ovina: técnicas de avaliação "in vivo" e na carcaça. Pelotas: Universidade Federal de Pelotas, 2003. 73p.

PALMIQUIST, D.L.; MATTOS, W.R.S. Metabolismo de lipídeos. In: BERCHIELLI, T.T.; PIRES, A.V.; OLIVEIRA, S.G. de (Ed.). Nutrição de ruminantes. Jaboticabal: Funep, 2006. p.287-310.

ROGÉRIO, M.C.P.; BORGES, I.; TEIXEIRA, D.A.B.; RODRIGUEZ, N.M.; GONÇALVES, L.C. Efeito do nível de caroço de algodão sobre a digestibilidade da fibra dietética do feno de Tifton 85 (Cynodon spp.) em ovinos. Arquivo Brasileiro de Medicina Veterinária e Zootecnia, v.56, p.665-670, 2004. DOI: 10.1590/S0102-09352004000500015.

SAEG: sistema de análise estatística e genética. Versão 8.0. Viçosa: UFV, 2007. 150p.

SALIBA, E.O.S.; FERREIRA, W.M.; PEREIRA, R.A.N. Lignin from Eucaliptus grandis as indicator for rabbits in digestibility trials. Tropical and Subtropical Agroecosytems, v.3, p.107-109, 2003.

SILVA SOBRINHO, A.G.; SILVA, A.M.A. Produção de carne ovina. Revista Nacional da Carne, v.1, p.32-44, 2000.

SILVA, D.J.; QUEIROZ, A.C. de. Análise de alimentos: métodos químicos e biológicos. 3.ed. Viçosa: Ed. UFV, 2002. 235p.

SNIFFEN, C.J.; O`CONNOR, J.D.; VAN SOEST, P.J.; FOX, D.G.; RUSSELL, J.B. A net carbohydrate and protein system for evaluating cattle diets. II. Carbohydrate and protein availability. Journal of Animal Science, v.70, p.3562-3577, 1992.

SULLIVAN, H.M.; BERNARD, J.K.; AMOS, H.E.; JENKINS, T.C. Performance of lactating dairy cows fed whole cottonseed with elevated concentrations of free fatty acids in the oil. Journal 
of Dairy Science, v.87, p.665-671, 2004. DOI: 10.3168/jds. S0022-0302(04)73209-9.

URANO, F.S.; PIRES, A.V.; SUSIN, I.; MENDES, C.Q.; RODRIGUES, G.H.; ARAUJO, R.C. de; MATTOS, W.R.S. Desempenho e características da carcaça de cordeiros confinados alimentados com grãos de soja. Pesquisa Agropecuária
Brasileira, v.41, p.1525-1530, 2006. DOI: 10.1590/ S0100-204X2006001000010.

WEISS, W.P. Energy prediction equations for ruminant feeds. In: CORNELL NUTRITION CONFERENCE FOR FEED MANUFACTURERS, 61., 1999, Ithaca. Proceedings. Ithaca: Cornell University, 1999. p.176-185.

Recebido em 28 de setembro de 2012 e aprovado em 28 de março de 2013 